\title{
Understanding what young people know: methodological and theoretical challenges in researching young people's knowledge and understanding of the Holocaust
}

Arthur Chapman \& Rebecca Hale

\begin{abstract}
This article draws on research into young people's knowledge and understanding of the Holocaust conducted by the UCL Centre for Holocaust Education (CfHE). Two questions are addressed: 'How can we theorise and measure development and progression in young people's historical knowledge and understanding of the Holocaust?' and 'How can empirical social scientific research methods be used to help us describe young people's knowledge and understanding of the Holocaust?' This article reviews methodologies developed by the CfHE and exemplifies a research tool and two complementary approaches to analysis, focused on young people's descriptions of the Holocaust.
\end{abstract}

Keywords: Holocaust education; progression in historical thinking; method and methodology

\section{Authors' correspondence}

Dr. Arthur Chapman

Senior Lecturer in History Education

Department of Curriculum, Pedagogy and Assessment

UCL Institute of Education

University College London

20 Bedford Way

London WC1H 0AL

arthur.chapman@ucl.ac.uk

Dr. Rebecca Hale

Research Associate

UCL Centre for Holocaust Education.

20 Bedford Way 
London, WC1H 0AL

r.hale@ucl.ac.uk

\section{Notes on contributors}

Arthur Chapman is Senior Lecturer in history education in the UCL Institute of Education. He works in initial education and supervises masters and doctoral students. Arthur is Associate Editor of the London Review of Education and The International Journal of Historical Learning, Teaching and Research, a member of the editorial boards of the International Review of History Education and the Curriculum Journal and was co-editor of Teaching History in 2007-2013. He was an editor of Constructing History, 11-19 (2009) and of Joined Up History (2015). He is Fellow of The Royal Historical Society.

Rebecca Hale is a Research Associate in the UCL Centre for Holocaust Education. She works within the Centre's research team, and is one of the lead authors of What do students know and understand about the Holocaust? Evidence from English Secondary Schools. She is leading a study into the impact of the Centre's professional development programmes for teachers and evaluates the Centre's Beacon School programme.

\section{Introduction}

It is widely agreed that it is important for young people to learn about the Holocaust, as the articles by Pearce and Pettigrew in this edition show. Given this agreement, it is necessary to understand the challenges that building knowledge and understanding of the Holocaust can present for young people, and to develop tools that will enable young peoples' knowledge and understanding to be assessed and evaluated.

This article addresses two questions. First, the historical question 'How can we theorise and measure progression in young people's historical knowledge and understanding of the Holocaust?' and, second, a methodological question 'How can empirical social scientific research methods and methodologies be used to help us describe young people's knowledge and understanding of the Holocaust?' We explore answers to these questions by drawing on the experience of large scale 
empirical work conducted by Foster, et al. and on wider research about progression in historical understanding. ${ }^{1}$

\section{Historical Knowing and Historical Understanding}

Developing 'competence' in disciplines and areas of knowledge is a complex matter that involves both a 'deep foundation of factual knowledge' and understanding 'facts and ideas in the context of a conceptual framework'. ${ }^{2}$

We can speak, for example, of knowing and understanding singular factual propositions (such as the proposition that 'Gavrilo Princip... pulled out a gun and shot at Franz Ferdinand, hitting him in the jugular vein') or collections of such propositions about aspects of the past. ${ }^{3}$ We can also speak of knowledge and understanding at a qualitatively different level, for example, the level of conceptualisation (as, for instance, in 'The assassination... was critical in setting off the chain of events that led to the First World War'). ${ }^{4}$ Some knowledge and understanding of both the factual and the conceptual is necessary to historical literacy since connecting together sequences of propositions about the past involves making conceptual connections (attributing causal links, measuring change, assessing significance, and so on). ${ }^{5}$

Conceptual knowledge and understanding can be differentiated into at least four aspects:

- Knowledge and understanding of general substantive concepts ('assassination') that serve to categorize events and developments and states of affairs in various ways;

- Knowledge and understanding of specific substantive historical concepts used by people in a particular historical period (e.g. 'The AustroHungarian Empire'); 
- Knowledge and understanding of domain specific procedural concepts, for example, historical causation (as in a 'chain of events that led to') that enable historical questions to be asked and answered; and

- Knowledge and understanding of historical 'colligation' - that is, of an interpretive process through which particular events and actions are synthesised into larger wholes that serve to designate and model largescale historical phenomena unfolding over time (such as 'the First World War'). ${ }^{6}$

Knowledge and understanding can be considered at various levels of resolution. ${ }^{7}$ We can distinguish between 'zoomed in' narrative comprehension that might be evidenced by the ability to 'tell' a human-scale story coherently, and comprehension that 'zooms out' from historical particulars to explore patterns of causality and change over generational timescales and at higher levels of abstraction (e.g. the histories of nations rather than of individuals). 'Zooming out' entails knowing how to use concepts to organise historical particulars ('the Arch-Duke') into higher level abstractions ('the Austro-Hungarian monarchy'). Higher level abstractions, such as the concept 'revolution', enable comparisons to be made between different contexts and episodes in history.

Comprehension, at these differing levels of resolution, can also be understood in terms of differing degrees of comprehensiveness - one might be able to include relevant details about one or about a number of dimensions of a narrative, one might be able to use this information to answer one question only or a number of questions, one might be able to use this information to answer questions of one type (e.g. 'Why?' questions) or of many types (such as 'What?', 'Why?', 'How? And 'So what?' questions), and so on. Comprehension can also be differentiated by degrees of reflexivity or meta-cognition. 


\section{Knowing and Understanding the Holocaust}

What is true of history in general is true of knowing and understanding the Holocaust. What does it mean to have 'knowledge' and 'understanding' of the Holocaust? What does it mean to have 'better' or more 'comprehensive' knowledge? What would it be to 'progress' in ones' knowledge and understanding and, in any case, how might we come to recognise and evaluate children's knowledge and understanding?

One approach to answering this question is to focus on the fact that 'the Holocaust' is a colligation. Like 'the Renaissance' or 'the French Revolution', the Holocaust is an interpretive concept that is used to bind together historical particulars (including events, actions, agents, ideas and so on) into a larger whole. One way in which we can differentiate understandings of the Holocaust is in terms, first, of the components that are colligated (or bound together) in particular understandings of the term and, second, of how these items are colligated into a coherent whole. Comparing two students' descriptions of the Holocaust might, for example, reveal:

1. Differences in content (one might begin in 1933 and another in 1941);

2. Differences in assumption about what is to be described (one might focus on policy and, thus, on the aims and actions of the perpetrators and another might focus on the experiences of the victims); and

3. Differences in assumption about the purpose of description (one might assume and analytic optic and focus on 'How?' and 'Why?' issues and another might assume an ethical optic and focus on commemoration or wider significance).

Colligations serve both to differentiate and also to enable comparison and generalisation. The colligation 'The French Revolution', for example, can enable the 
distinct nature and development of the events that it denotes to be modelled and to be compared and contrasted with other 'revolutions'. Colligations can be appraised in terms of both of these functions and we might compare two different conceptualisations of the Holocaust by asking:

1. How effectively and comprehensively do they identify, model and understand the Holocaust as an historical phenomenon and in terms of its origin, nature, development and consequences?

2. How effectively and comprehensively do they identify and understand the Holocaust as genocide - as the founding instance of a wider class of historical phenomena of a specific kind. ${ }^{8}$

\section{Researching Children's Knowledge and Understanding of the Holocaust: Methodological challenges and considerations}

Historical knowledge and understanding are complex and this circumstance is further compounded by a number of research considerations for researchers who are exploring the nature of students' knowledge and understanding of the Holocaust. The scope of literature on both Holocaust education and research methods precludes us from providing a thorough discussion of all possible considerations and issues, but some illustrative examples are presented here.

One of the most important concerns for researchers is to decide and define the concepts that they are examining. As we have seen above, knowledge and understanding can be modelled in various ways and examined at varying degrees of resolution. These considerations are likely to be further complicated when examining Holocaust knowledge and understanding in view of research conducted by Pettigrew et al. ${ }^{9}$ Their research showed that history teachers often prioritised teaching aims which were not specific to 
the historiography of the Holocaust, but instead had a moral and civic dimension; for example 'to develop an understanding of the roots and ramifications of prejudice, racism and stereotyping in society' and 'to learn lessons of the Holocaust and to ensure that a similar human atrocity never happens again'. Thus, it is important for research to reflect on the potential implications of these 'lessons', and the extent that they enrich and/or distort students' historical knowledge and understanding of the Holocaust.

The conceptual differences between knowledge and understanding should not be overlooked by researchers and the terms should not be treated as synonymous. ${ }^{10}$ This issue becomes all the more pertinent when one reflects that research often utilises multiple choice questions to assess students' knowledge. One of the reasons for opting for this approach is that multiple choice questions provide a means to collect data from a large sample that can be quickly and objectively scored. ${ }^{11}$ This enables researchers to collect numerical data, look at patterns in their data set and conduct statistical analyses. However, those utilising this approach are often limited to measuring students' ability to recall singular factual propositions. Typically, as argued by Bischoping multiple choice questions do not access critical thinking skills and instead give a measure of knowledge based on rote memorisation. ${ }^{12}$

The limitations of multiple choice questions to measure understanding are demonstrated by Carrington and Short. ${ }^{13}$ In individual interviews they asked students: what was the Nazi stereotype of a Jew? They noted that while a number of students said 'evil', 'inferior', or 'wealthy', they were unable to elaborate or show any real understanding in this area when prompted. This is an issue for researchers, because it reminds us that students may not have an accurate or detailed understanding of a given topic, even if their answers might first appear to be in the right ballpark. The risk here is that multiple choice questions are less likely to detect the nuance in students' 
understanding. Certainly, examples of this issue were found in the research by Foster et al. ${ }^{14}$ For example, in their survey the majority of students $(60.6 \%)$ correctly identified ghettos as areas where Jews were forced to live separately from non-Jews. However, the focus groups revealed that students' understanding of the ghetto system was typically rudimentary. Students were often unsure about where ghettos were geographically located and appeared unfamiliar with the connection between the development of antiJewish policy and ghettoisation. Thus, we are reminded that even where students select the correct answer in multiple choice questions, they are not always able to elaborate or explain their choice.

In order to explore this issue, Foster et al. asked students to indicate their level of confidence in their answers. ${ }^{15}$ For instance students were asked: in which country did the largest number of killings of Jewish people actually take place? Just over one third of students correctly identified German occupied Poland, suggesting they had sound knowledge on this topic. However, of these students, a third of them said they either guessed the answer or were not very confident about it. Without this measure of confidence, it would have appeared that a greater number of students knew this information than was actually the case.

One alternative to multiple choice questions is to collect more detailed data from students. Ivanova used critical discourse analysis to examine essay style responses to the statement: 'Please write about the Holocaust (the mass extermination of Jews during the Second World War) ${ }^{16}$ The merit of this approach was that students were free to include any information they deemed relevant. This is likely to have facilitated some of the rich findings that emerged in the data, for example, students who used an 'openly antisemitic discourse' as well as a 'camouflaged antisemitic discourse', and is an example of the value of collecting qualitative data like this. However, research of this nature is typically 
presented with various caveats pertaining to small sample sizes, the complications of generalising the findings, and an acknowledgement that the interpretation of the data can be vulnerable to scrutiny because of concerns about researcher bias. ${ }^{17}$

Another crucial point for consideration is that a study of students' knowledge and understanding of the Holocaust will typically provide some sort of commentary or judgement about the level, breadth or depth of their knowledge, and in doing so allude to some sort of benchmark. That is, the researcher - either explicitly or implicitly - has certain expectations of what students should know. This presents a paradox. Of course to collect data, the researcher needs to identify and/or create suitable questions. However, as Jebwab points out this is a challenge as there is no consensus around a common set of questions to establish benchmarks to indicate satisfactory knowledge. ${ }^{18}$ This is an issue recognised in the research by Foster et al. The authors acknowledge that "any empirical examination or attempt to measure 'knowledge' is an inherently complex and contested enterprise."19

Researchers and educators need to be aware that where studies conclude students have high or low levels of knowledge of the Holocaust, what they are actually concluding is that based on the questions used in that study students demonstrate high or low knowledge. These same students may show greater or lesser knowledge of the Holocaust if presented with a different set of questions. This situation was highlighted by Jedwab who contrasted the conclusions of two surveys. One survey, commissioned by the American Jewish Committee in 2005, found that knowledge of death/concentration camps amongst the Swedish public was very high based on their ability to identify Treblinka, Dachau, and Auschwitz. ${ }^{20}$ Whereas in another survey with teachers in Sweden conducted for the Living History Forum, participants were deemed to have low 
knowledge because they were not aware that murdering Jews was not a primary objective at Dachau and Bergen-Belsen.

Some studies have avoided grappling with the content and nature of questions to tap into knowledge and understanding by asking respondents for their perception of their knowledge (without actually using substantive knowledge questions). This also avoids the complexity of defining a benchmark for knowledge. However, it is arguable that some measure of Holocaust knowledge is preferable to no measure because students' perceptions of their knowledge are not always accurate. For example, Foster et al. asked: if a member of the military or police refused an instruction to kill Jewish people, what do you think would be most likely to happen to them? Two thirds of students incorrectly said that the military or police would be shot for refusing to obey an order. ${ }^{21}$ Of these students, $67 \%$ were 'fairly confident' or 'very confident' of this answer. Consequently, researchers should be cautious about being too reliant on self-assessment as a measure of knowledge because discrepancies between what students think they know and what they actually know can emerge in certain areas.

These considerations, while complex, do not mean researchers should abandon measurement of knowledge through survey methods. As Bischoping states: "to say that survey methods suffer certain limitations is not alone an adequate argument for change: every method has its problems. But once limitations have been identified, researchers need to make informed decisions about which ways of defining and measuring knowledge yield the most meaningful results. ${ }^{22}$ Researchers are encouraged to identify and create reliable questions to give some insight into students' knowledge including 'closed' multiple choice questions and 'open' questions with space for students to give answers they construct themselves. 
Researchers have a number of methods they can draw on when exploring young people's knowledge and understanding of the Holocaust and can also combine different approaches. According to Johnson, Onwuegbuzie and Turner "mixed methods research is the type of research in which a researcher or team of researchers combines elements of qualitative and quantitative research approaches (e.g., use of qualitative and quantitative viewpoints, data collection, analysis, inference techniques) for the broad purposes of breadth and depth of understanding and corroboration". ${ }^{23}$

Proponents of mixed methods research argue that its value is in enabling researchers to be more flexible and holistic in their investigative techniques. ${ }^{24}$ Indeed, a study incorporating both methods can benefit from the merits of each method ${ }^{25}$ and in doing so help to counteract some of issues that can arise when using a single method. ${ }^{26}$

In view of the conceptual complexity of Holocaust knowledge and understanding, a mixed methods approach to research in this area is likely to be more illuminating. Decisions regarding the most appropriate methodology should be guided by the research questions, ${ }^{27}$ and in many studies a mixed method design will provide the best means of answering these questions. ${ }^{28}$ This was the case for the research by Foster et al. ${ }^{29}$ One aim of this study was to find the scope of Holocaust knowledge in secondary school students across England; to get a sense of what young people did and did not know about the Holocaust. This type of research question lends itself to a positivist approach whereby the prevalence of responses among a large sample of students can be assessed, and analyses that measure the relationships between variables (like correlation and regression) can be performed to look at variables that are associated with knowledge. In the case of Foster et al, this made it possible to collect and analyse data from almost 8,000 students. 
However, while the measurement of knowledge in a large-scale survey can answer the 'prevalence' questions (e.g. how many students know that 6 million Jewish people were murdered by the Nazis), it does not tell us why students do or do not know this, and what 'knowing' this piece of information means to them and their understanding of what happened during the Holocaust. These types of research questions can only be explored by drawing on an interprevitist approach. Consequently, a crucial element of the research by Foster et al. was to carry out focus group discussions with over 200 students. $^{30}$

In addition to the question of research instruments and data collection strategies, consideration needs to be given to methods of data interpretation and the sense that is made of research data, as with any other kind of sense making, arises from interaction between data and modes of data interrogation. Analysis techniques can be differentiated in terms of their complexity - from a simple word count conducted to identify patterns in the incidence and distribution of terms in a corpus - to procedures that aim to work back retroductively from a word count distributions to mechanisms explaining observed patterns in data. ${ }^{31}$ Analysis techniques can be differentiated in terms of the formal relationships that they can identify (distribution, association, correlation, causation and so on). Analysis techniques can also be differentiated in terms of the extent to which they make explicit assumptions and decisions, prior to analysis, about what to look for and the extent to which they aim, as Grounded Theory does, to derive analytical categories in an inductive manner from the inspection of data. ${ }^{32}$

This article will dramatize some of the issues we have raised by exploring one aspect of the large data set collected by the UCL Centre for Holocaust Education (CfHE). We will focus on one questionnaire item only - an item that called for an open text response. We will, first, summarise the analysis conducted by the Centre to illustrate the power of large scale quantitative analysis of qualitative data as a strategy to explore the 
question 'What do young people know and understand about the Holocaust?' ${ }^{33}$ We will then report a new analysis of a small subsample of this data using a different analytical technique that aims to operationalise substantive knowledge and colligation in the ways identified in Section 3 above.

\section{5. 'Can you describe in one or two sentences what you think the Holocaust was?': Method and interpretation}

\subsection{The Centre for Holocaust Education Study}

The data analysed in this article is taken from the UCL Centre for Holocaust Education's national study to explore knowledge and understanding of the Holocaust in England's secondary schools ${ }^{34}$. In this study 7,952 students aged from 11 to 18 years completed a survey and 244 students took part in focus groups. ${ }^{35}$

Broadly, the survey was split into three sections: students' attitudes towards salient variables (e.g. beliefs in a just world), substantive knowledge of the Holocaust, and experiences of learning about the Holocaust. The substantive knowledge questions were mainly given in a multiple choice format where students had to select the correct answer from a choice of several options. For example, students were asked: in 1933, what percentage of the German population was Jewish? The response options were: less than $1 \%$; approximately $5 \%$; approximately $15 \%$; more than $30 \%$. Students were also asked a small number of open questions where they could write their answer in the text box provided. We focus on one of these questions below.

\subsection{Describing what the Holocaust was: Schemata and form}

Foster et al. asked students the question -

Please can you describe in one or two sentences what you think the Holocaust was? 
A text box was provided for students to construct their own answer. A total of 6,133 students responded to this question providing a rich and extensive data set. Their descriptions ranged from single-word answers to short paragraphs of up to 250 words. ${ }^{36}$

A summary of the analysis of this data reported in Foster et al.'s study What do Students Know and Understand About the Holocaust is presented in this section. ${ }^{37}$ In the remainder of the article we go on to examine a subsample of the data collected by this item to explore progression in substantive knowledge and colligation.

The question was one of a number of items in the questionnaire that aimed to understand the substantive knowledge and understandings of the Holocaust held by students by age group and across the data set as a whole and to establish if this content was patterned in regular ways: in other words, the aim was to establish if students' answers shared a common form.

In keeping with this focus, the analysis was primarily on the content of students' answers and in two senses. First, by making frequency counts of the data set for all answers in the data set and by exploring patterns of prominence and distribution that this presented. Students were most likely to make at least one reference to 'Jews', 'Jewish people' and/or 'the Jewish faith'. The second most likely term to be referenced was 'killing' followed by 'Hitler'. Second, in addition to the frequency counts, a 'coding frame' was created identifying narrative elements that might or might not figure prominently in students' descriptions, as follows:

1. Named or otherwise identified victims of the Holocaust.

2. Named or otherwise identified perpetrators of the Holocaust.

3. Specific actions undertaken during the Holocaust.

4. An indication of the scale of the Holocaust.

5. A timeframe for the Holocaust.

6. A geographic location associated with the Holocaust.

7. Any indication of a possible cause of the Holocaust. ${ }^{38}$ 
A subsample of 2,987 responses were analysed using this frame to record whether or not students made reference to items in each category in their descriptions. The degree to which these items were or were not present in student year groups' descriptions was then recorded and plotted graphically. Two very striking findings emerged from this formal analysis:

- In all age groups, students scored highly on the first three elements in the coding frame - victims, perpetrators and actions.

- The same broad pattern held, with minor variations (small increases in the incidence of items on the remaining dimensions of the coding frame) regardless of whether or not students had studied the Holocaust in school.

Although the pattern of responses was similar across year groups, students in Year 9 and above were more likely to identify actions and victims than younger students in Year 7 and 8 (that said, references to actions and victims were still prevalent in the answers of Year 7 and 8 students). Students in years 12 and 13 were more likely to make reference to timeframe and location than younger students, although the proportion of students including these details in their answer was still relatively low in comparison to the number of references to actions, victims and perpetrators.

Clearly, these findings can tell us a great deal about the challenges associated with building knowledge and understanding of the Holocaust. Foster et al. conclude that a key influence on student thinking in all age groups is a 'collective conception' of what the Holocaust was and of how it should be thought about, embedded in the wider culture, and that this has significant impacts on the substantive model of the Holocaust that students build. Progressing understanding is likely to entail, first, being aware of the affordances 
(such as knowledge of camps like Auschwitz) and constraints (such as lack of awareness of the importance of the Holocaust 'by bullets') that 'collective conceptions' yield and, second, targeting teaching to address these constraints. ${ }^{39}$ Foster et al.'s coding frame also enables progression, in the sense of increasingly detailed substantive knowledge of particulars (for example, of location, cause, scale and timeframe) to be observed over time. ${ }^{40}$

In the next section of this article we explore the additional insights that can be gained into questions of progression and substantive conceptual development by exploring Foster et al.'s data using qualitative tools focused on the grammar of student thinking, or, more precisely, on how they use, combine and sequence content in their descriptions of the Holocaust.

\subsection{Describing what the Holocaust was: Grammar, transitivity, ontology}

Providing a description of the Holocaust is, among other things, a linguistic task involving language choices. We can think of linguistic choices as operating on two dimensions:

- A lexical dimension, relating to word choice; and

- A grammatical or syntactic dimension, relating to sequencing and combination and to the ways in which items are combined in narrative time or, as it were, from left to right on the page.

Foster et al.'s primary focus was on mapping the content included in students' descriptions of the Holocaust - at, as it were, the 'lexical' level in terms of the extent to which items of different types were included and with what degree of accuracy. They then worked back from these data to schemata or 'collective conceptions' that may have informed the choices that respondents made. Our focus in what follows is literally 
grammatical and looks, primarily, at how students sequence and combine items in their descriptions of the Holocaust.

Foster, et al.'s 'coding frame' looks at patterns in the presence and the prevalence of elements of various types in students' descriptions of the Holocaust. The analysis that we report below examines the grammar of student responses and undertakes a 'transitivity' analysis of students' responses. In addition, we report an analysis of the 'ontologies' implied in the language that students used to talk about the Holocaust - in other words, we explore how far students spoke of the Holocaust as a time 'period' or 'place', or as made up of 'events', 'actions' and / or 'processes'.

By looking at grammar we explore the possibility that structure, at the level of linguistic form, may reveal key dimensions of student thinking. It seems probable that both the question 'What narrative elements do students include (and not include) when describing the Holocaust?' and the question 'What grammar do students use when they link together component items in their descriptions?' may be helpful in differentiating students' responses to the task of historical description and, thus, in revealing some of the cognitive challenges that learning about the Holocaust can present.

\section{Data Analysis and Discussion}

In order to explore these possibilities, a small sample of 90 cases from Foster et al.'s data set was selected. The sample is small as our purpose here is exploratory - we are seeking to scope the potential of a mode of analysis rather than to make generalizable claims.

Thirty cases were randomly selected from the Year 12 (16-17 year-olds) data and 30 cases each were randomly selected from the Year 7 (11-12 year-olds) and Year 8 (1213 year-olds). We wanted to compare answers by age and this sample enables (a) a comparison over 5 years (Year 7: Year 12) and (b) a check on conclusions (where 
contraindications in Year 8 are observed to patterns posited on the basis of Year 7 to Year 12 comparisons then the attribution of impact to age becomes harder).

The cases were inputted to the qualitative analysis software NVivo and analysed deductively. That is to say we began with categories and then coded data to categories on the basis of best fit. This procedure - rather than an inductive one where categories would emerge from the data - was used because we were aiming to test the value of particular modes of analysis rather than to ground our mode of analysis in the data in an emergent manner. $^{41}$

A number of categories were used in analysis. First, we undertook a 'transitivity' analysis, drawing on resources in systematic functional linguistics. ${ }^{42}$ Transitivity analysis is both relatively simple and also theoretically salient in the sense that its focus is on how grammar constructs 'representation'. As Halliday and Matthiessen explain a 'clause has meaning as a representation of some process in ongoing human experience' and to conduct a transitivity analysis is to explore how respondents distribute contents to the grammatical roles 'process', 'participant(s)' and 'circumstances' when representing the world in language. ${ }^{43}$ Although we started out with a 'coding frame', like Foster et al., our frame was purely functional and without further semantic content and it enabled us to explore to 'who/m' or to 'what' respondents attributed functions and what 'processes' they included in their descriptions.

In addition to looking at function we also looked at another more nebulous dimension of linguistic form by asking the question 'How is the Holocaust positioned as an entity in students' descriptions?', or, metaphorically, 'What tacit ontologies do students appear to deploy?' Again we began with a coding frame - explained in the tables that follow below - rather than inductively. However, again, the frame was purely formal (so, for example, we asked 'Do students speak of the Holocaust as 'an event'?'). 
Finally, and taking our cue here from Foster et al. and from earlier studies, we coded our sample in terms of the conceptualisation of the Holocaust as a genocide and looked for patterns of presence or absence of relevant conceptual attributes in students' answers. ${ }^{44}$ Again, we began with a coding frame but this time, like Foster et al., the frame was substantive - coding student definitions against pre-set categories reflecting conceptual attributes. Our aim in this element of the analysis is to explore the extent to which respondents demonstrate explicit awareness of pre-specified aspects of the meaning of the concept and to explore relationships between this aspect of their thinking and the form of their descriptions.

\subsection{Transitivity Analysis}

'Transitivity' relates to ways in which grammatical relationships construct agency, for example by attributing 'subject' and 'object' roles. Our transitivity analysis explored the sample of student responses by, in effect, asking the question 'Who does what to whom?' Patterns of transitivity were identified in the data by analysing respondents' descriptions in terms of:

1. Participants in the Holocaust present in responses and their distribution in the roles of 'Actors' (the subjects of verbs) or 'the Acted-upon' (semantic objects) in the Holocaust and to whom these roles were assigned; ${ }^{45}$

2. Processes identified by respondents to characterise what happened during the Holocaust, either in the form of verbs (e.g. 'killed') or in terms of nominalisations - noun phrases taking the role of verbs (for example 'the systematic killing of... by...'); ${ }^{46}$

3. Circumstances identified by respondents that provide information about the situation or context in which the process/es identified in verbs or nominalisations 
took place - for example, information about spatial circumstances (e.g. 'in Germany').

\section{1.i. Transitivity: Participants}

The 'Actors' and 'Acted-upon' of processes identified in our sample were coded into lowinference categories, sticking as closely as possible to the phrases that respondents used. Tables 1 and 2 present this data analysed by year group.

\section{INSERT: Table 1 and Table 2}

A number of suggestive patterns are surfaced by the analysis reported in these tables. Overall, in all year groups, the 'Acted-upon' figured more prominently than 'Actors' - in total 79 terms identifying 'Actors' and 154 terms identifying the 'Actedupon' were found - and the Holocaust was understood more in terms of the 'Acted-upon' than in terms of the 'Actors'. Although the contrast between Year 7 and Year 12 might suggest that this pattern becomes more prominent with age - the items identifying 'Actors' constitute $42.4 \%$ of 'participants' identified by the Year 7 sample and $27.2 \%$ of the Year 12 sample - the Year 8 figure (28.3\%) does not support this inference.

Some suggestive patterns in the distribution of 'Actors' to broad types are apparent in this data over time. In both Year 7 and Year 8 'Hitler' and 'The Germans' are the two most common 'Agents' (accounting for $56.4 \%$ and $73.3 \%$ of 'Agents' respectively). The figure for Year 12 , by contrast, is $22.7 \%$. There is some suggestion that 'Actors' become more differentiated and specific by age. Although mentions of 'Nazis' fluctuate over time, phrases that collocate 'Nazi' and political concepts (such as 'party' and 'government') increase over time: summing rows 8-10 indicates that mention of these 
items increases by $28 \%$ between Year 7 and Year 12. A more striking pattern emerges when all references to the Nazis are summed. Excluding the figures in row 11 (where Hitler also figures) dramatic increases are apparent in reference to this political party / movement and they increase from around $20 \%$ in both Years 7 and 8 to $50 \%$ in Year 12.

Similar patterns of increased specificity and differentiation by age are suggested by the 'Acted-upon' data (Table 2), although again there is some contraindication in Y8, where greatest mention is made of the undifferentiated category 'Jews' (row 1). Mentions of generalised human terms for victims (rows 16-19) decline with age (from $21.10 \%$, to $5.30 \%$ and then to $1.7 \%$ ) and differentiation of named 'Acted-upon' groups (rows 2-9) increases over time (from $5.3 \%$, to $10.4 \%$ and then to $30.6 \%$ ).

In summary, the 'participant' analysis shows that, for all groups, greater mention is made of the 'Acted-upon' than of 'Actors' and that, perhaps in the case of 'Actors' but more clearly in the case of the 'Acted-upon', participants become more differentiated and specific over time.

\section{1.ii. Transitivity: Processes}

Processes were differentiated into verbs (rows 1-6 in Table 3 below) and nominalisations (row 7) and the former were categorised as 'material' (e.g. 'were killed', 'were forced'), 'mental' (e.g. 'believed that', 'wanted'), 'relational' (e.g. 'treated as', 'to do with'), 'existential' (e.g. 'took place', 'occurred') and 'verbal' (e.g. 'told'), drawing on an existing generic model of process categories. ${ }^{47}$ Table 3 reports the outcomes of this analysis.

\section{INSERT: Table 3}

Some clear patterns of contrast are apparent in the Table over time. In both Year 7 and Year 8, 'material' processes (row 1) dominate representing $80 \%$ and $75 \%$ of 
processes coded, respectively. In Year 12, by contrast, 'nominalisation' (row 6) dominates $(37.7 \%$ of processes coded) and material processes represent only $30.5 \%$ of processes coded. A small but consistent increase occurs in mentions of mental processes over time (row 2) and another consistent, but more dramatic, pattern of increase is apparent for 'existential' processes (row 4). This last pattern is related to the change in incidence of nominalisation, as nominalisations were frequently accompanied by existential processes, for example in this Year 12 description:

The mass extermination of Jews that took place while Adolf Hitler was dictating Germany. ${ }^{48}$

Increased use of nominalisation by age group also helps to account for the decline in mention of participant 'Actors' observed in the analysis of Table 1. Nominalisation enables abstraction and semantic density, by compressing complex processes into a noun or noun phrase - as the contrast between verbal phrases such as 'were killed' and nominalisations like 'mass extermination' shows (the latter contains the idea 'were killed' and additional content as well, including a clear sense of intention, possible connotations of bureaucratic process, and so on). Nominalisation can also have the effect of obscuring human agency, as both the following example and the example cited earlier in this section indicate:

The Holocaust was the genocide which occurred during the second world war under Hitler's dictatorship. Millions of Jews, homosexuals, disabled people and other minority groups were murdered in order to 'purify' Germany and create a 'master race'.

Year 12

Here the Holocaust 'occurs' (an existential verb without a subject) and the 'Actors' with command responsibility become a contextual circumstance ('The 
Holocaust.... occurred... under Hitler's dictatorship'). In this case, the sentence that describes the actions that 'the genocide' consisted of ('Millions... were murdered') lacks an explicit 'Actor'. There is no clear answer available to the question 'Who murdered them?', although the act is linked to a disembodied intention ('in order to 'purify' Germany') that was realised 'under Hitler's dictatorship'.

Table 4 analyses the nominalisations found in the data samples and their pattern of use by age group and also by the lexical features of the terms.

\section{INSERT: Table 4}

In addition to the marked increase in incidence in nominalisation noted already, the table reveals the following pattern: the nominalisations used by Year 7 and Year 8 respondents are mostly everyday words (items in word type A represent $66.7 \%$ and $60 \%$ of the nominalisations observed, respectively) but the opposite is the case in Year 12 where $63.6 \%$ of nominalisations are Latinate abstractions connoting bureaucratic and / or legal processes or offences (word type B). In addition, one of the Year 12 nominalisations uses period terminology (word type C), a Nazi euphemism.

\section{1.iii. Transitivity: Circumstances}

Eight circumstance codes were created to reflect the range of considerations that respondents identified when contextualising participants and processes. Responses were coded for mention of 'spatial location' (e.g. 'in Germany' or 'in ghettos away from society'), of time (e.g. 'roughly $1938-1945$ ' or 'in the $1930 \mathrm{~s} / 1940 \mathrm{~s}$ ') of the 'means' by which processes were implemented (e.g. 'by gassing') and for mention of information about the general 'situation' (e.g. 'during the second world war under Hitler's dictatorship'). ${ }^{49}$ Material that accounted for motivation or aims was coded as 
'explanation' (e.g. 'in order to 'purify' Germany and create a 'master race') and mention of results was coded as 'consequences' (e.g. 'resulted in WW2'). Mention of numbers of victims was coded as 'scale' (e.g. 'six million') and evaluative comment was coded as 'evaluation' (e.g. 'horrible concentration camps' and 'a terrible time in history').

\section{INSERT Table 5}

It is hard to discern clear patterns of increase or decline in references to circumstances with the exception of references to circumstances of 'situation' (row 4), where decrease over time is observed, explanation (row 5), where increase over time is observed, and 'evaluation' (row 8), where decrease over time is observed.

When talking about circumstances of situation, some respondents in all three year groups mention the war (71.4\% Year 7 and around $40 \%$ of Year 8 and 12) and political circumstances in Germany (14.3\% of Year 7, 45.5\% of Year 8 and $53.8 \%$ of Year 12). Year $7(14.3 \%)$ and Year $8(9.1 \%)$ also make reference to concentration camps. References to circumstances of situation are exemplified by the following responses:

The holocaust was part of World War 2, it was started from when the Germans began invading other countries.

Year 7

Hitler and the Nazis captured all Jews, shaved their heads, put them into the same outfits so they're all the same. Made them work all day and then finally gassed them until they died.

Year 8

The Holocaust took place during the Second World War, when Germany was run by Hitler and the Nazis.

Year 12 
It is difficult to draw any clear conclusions from these comments about circumstances, although the lack of detailed reference to camp contexts in Year 12 data is suggestive, indicating, perhaps, a broader contextual focus rather than a focus on actions and events (an inference consistent with earlier findings on nominalisation). The decrease in explicit evaluative statements over time is hard to interpret also. Two of the Year 12 sample make evaluative comment in passing through the use of the adjective 'innocent'. Year 7 and Year 8 were more prone to comment of this nature (adjectives such as 'terrible', 'horrid' and 'bad') but, again, there were few instances of evaluative comment and two striking outliers. One, in Year 7, made evaluative comment on the Holocaust by references to Stalinism, commenting that it was:

Almost the same as Joseph Stalin. 7.8 million. He also had death camps in Russia.

Year 7

Another, in Year 8, passed judgment on the historical significance of the Holocaust commenting:

The Holocaust was one of the worst cases of genocide in the history of the human race.

Year 8

Examination of comments on explanatory circumstances does, however, lead to some suggestive contrasts in the qualities of the answers offered by the different age groups. Table 6 analyses these differences.

INSERT: Table 6 
The majority (81.8\%) of the explanations offered by Year 12 are political and ideological in character, as exemplified by the following two responses, coded, respectively, under the 'political' and 'ideological' categories:

Hitler used the Jews as a scapegoat, blaming them for all of Germany's problems.

Year 12

The extermination of certain groups which the leaders of the Nazi Party saw as less than human, these included Jews, Homosexuals, Communists, Romany Gypsies etc.

Year 12

Almost all of the explanations offered by the other age groups fall into the remaining categories, as exemplified by the following responses coded, respectively, under the 'religious', 'personal animosity' and 'image' categories.

Many people were killed because of their religion.

Year 7

[The] Holocaust was when Hitler was against the Jewish people...

Year 7

Genocide of millions because they didn't fit an image.

Year 8 and 9

Overall, consideration of 'circumstances' provided by participants to contextualise the Holocaust is consistent with findings in the previous two sections of this article - Year 12 are more prone to treating the Holocaust in an abstract and analytical manner than younger students. One clear difference emerges also: the Year 12 sample 
provide more comment on explanatory circumstances than Year 7 and Year 8 and demonstrate greater understanding of the role of ideology in explaining the Holocaust.

\subsection{Ontological Analysis: What was the Holocaust?}

In addition to grammatical analysis, students' responses were analysed 'ontologically' to understand the kind of thing students treated the Holocaust as when they wrote about it. 'Ontological' is intended metaphorically in this analysis - the proposition is not that students have a worked out philosophical position on the identity of the Holocaust as a phenomenon. Nevertheless, it is interesting to note marked differences in the ways in which students write about the Holocaust, 'as if' it were an entity of a particular kind and it may, perhaps, be valuable to consider if there are relationships between how students wrote about the Holocaust and other aspects of students' thinking revealed in the analysis reported in earlier sections of this article.

Where respondents wrote about the Holocaust as something that could be attributed to the agency of an individual or a collective human actor, a response was coded as instantiating an 'act' ontology, as exemplified by the following response:

Something that Hitler did to... Jews...

Year 7

Where respondents wrote about the Holocaust as something that could be described as simply happening, without directly attributing its occurrence to a direct human agent or agency, a response was coded as instantiating an 'event' ontology, as exemplified by the following response:

A death of Jews on gas chambers.

Year 8 
In the one instance where the Holocaust was represented as a human entity, the response was coded as instantiating an 'person' ontology:

People who were held hostage in a prison.

Year 8 and 9

Where respondents wrote about the Holocaust as a 'time' or as a 'period', responses were coded as instantiating an 'period' ontology, as exemplified by the following response:

It was a time when Jewish people were discriminated and killed for their religion.

Year 8

Where respondents wrote about the Holocaust as a particular location, responses were coded as instantiating a 'place' ontology, as exemplified by the following response:

A German camp where Jewish people were killed by the 'shower' which was a gas room Year 7

Where respondents wrote about the Holocaust as a sequence of events connected by a purpose and/or as taking place over a period of time (rather than as a single event or a series of events connected contingently), responses were coded as instantiating a 'process' ontology, as exemplified by the following response:

The final solution as orchestrated by the Nazi party led by Adolf Hitler to remove via extermination undesirables from the European populace e.g. Jews, Homosexuals, gipsies etc. which took place from roughly 1938-1945.

Year 12

Table 7 reports the distribution of ontological codes and reveals clear patterns of change by year group. 
INSERT: Table 7

As the table shows, the incidence of 'act' and 'period' ontologies declines consistently with age and the incidence of 'process' ontology increases dramatically over time (by just under a factor of 10 between Year 7 and Year 12). As the example of process ontology cited above suggests, there is a link between this mode of thinking and nominalisation, an observation supported also by the twenty-two instances of nominalisation reported in the Year 12 data set (Table 4 above).

\subsection{Conceptual Analysis: Understanding Genocide}

The Holocaust was a genocide - a member of a class of events with particular defining features - and, of course, the term itself arose during the Holocaust and partly in response to the events of the Holocaust. How far did student responses to the task of describing 'what the Holocaust was' show clear appreciation of the genocidal nature of the Holocaust?

The analysis that follows explores this issue on three dimensions. First, the dimension of totality, relating to the extent to which students appreciate the genocidal aim animating the Holocaust, to completely destroy a people, biologically and culturally. Second, the dimension of exclusivity, relating to the extent to which students appreciate the fact that genocidal intent of the Holocaust was uniquely directed at the Jews. Third, the historical dimension, relating to the extent to which respondents do or do not model the Holocaust as evolving over time towards its exclusive and genocidal goal.

A number of possible positive answer categories follow from these dimensions and six are used in the analysis below:

- The category 'Genocidal and exclusive' which understands the Holocaust as an attempt to completely destroy the Jewish people; 
- The category 'Genocidal and inclusive' which understands the Holocaust as an attempt to completely destroy a number of peoples and/or groups;

- The category 'Non-genocidal and exclusive' which understands the Holocaust as a project of mass murder and/or persecution directed at Jewish people, without explicitly understanding its aim as their total destruction;

- The category 'Non-genocidal and inclusive' which understands the Holocaust as a project of mass murder and/or persecution directed at a number of peoples and/or groups, without explicitly understanding its aim as their total destruction;

- A 'Static differentiated' category which understands the Holocaust as genocidal in intent towards Jews but also as a project of mass murder and/or persecution directed at a number of other groups, without explicitly understanding its aim as the total destruction of these other groups; and

- A 'Dynamic differentiated' category, similar to the previous category but in which the genocidal nature of the Holocaust is understood as evolving over time and becoming genocidal in intention towards Jews at some point in this evolution.

Table 8 reports the outcomes of applying these categories to our sample of responses and notes patterns of difference by age group.

\section{INSERT: Table 8}

Comparisons between the year groups must be tentative, given the large number of the Year 8 sample who did not offer material relevant to the conceptual elements analysed by the table. The data does, nevertheless, suggest some increase over time in appreciation of the totality, or genocidal nature, of the Holocaust: whereas $50 \%$ of Year 12 respondents were coded in rows 1 and 2, only $26.7 \%$ of Year 7 and $13.3 \%$ of Year 8 respondents were. There is little evidence of movement towards exclusive understandings 
of the Holocaust and, in fact, some evidence of movement towards an inclusive understanding: whereas $16.7 \%$ of both Year 7 and Year 8 were coded in rows 2 and 4, the figure for Year 12 was $23.3 \%$. The table also shows very low incidence of a 'static differentiated' understanding of the Holocaust (1 case in 90) and no incidence of a 'dynamic differentiated' understanding. Table 9 exemplifies the five populated categories in the table, selecting across the three age groups.

\section{INSERT: Table 9}

\section{Conclusion and overall discussion}

In summary, our findings suggest a number of conclusions about progression in student thinking in our data sample over time, as follows:

- Some indication that students become more specific in their descriptive references to 'Actors' and the 'Acted-upon' was observed, demonstrating greater reference to substantive political concepts ('e.g. the 'Nazi Party');

- Some indication that students' descriptions become more abstract and less personalised in their representations of 'Actors' was observed (e.g. fewer references to 'Hitler');

- Some movement was observed from 'material' to 'mental' processes, a shift that is likely to be linked (as the 'mental' processes attribute aim and intention) to increases in the incidence of explanation (below);

- Some increase was observed in the use of nominalisation by age (particularly and dramatically so in Year 12), showing increased levels of both abstraction and semantic density and complexity in description (as, for example, in the contrast between 'killed' and 'mass extermination');

- Increased reference to circumstances of explanation was observed, despite the fact that students were asked to describe rather than explain, perhaps suggesting 
increased understanding of the importance of ideology to the explanation of the Holocaust;

- Some movement from 'act' and 'event' to 'process' when describing the Holocaust was observed, again linked to increased use of nominalisation; and

- Some evidence of increased appreciation of the importance of the ideological intention underlying the Holocaust (integral to the Holocaust's genocidal dimension) was observed.

Our analysis needs must be tentative, given our small sample and exploratory intention. Nevertheless, these findings are suggestive in their implications for understanding progression and how it might be theorized in the case of substantive concepts and historical colligations like 'the Holocaust'.

Many of these findings are consistent with what research on second-order, or procedural historical, understandings might lead us to expect. The focus on Hitler and on an 'act' ontology of the Holocaust, for example, chimes with findings on younger children's tendency to 'agentify' historical explanation and to attribute change and action in the past to the intentional action of specific historical agents. ${ }^{50}$ An implication, here, is that focusing on the development of historical content knowledge alone is unlikely to guarantee increasingly sophisticated understandings of the past, since how pupils understand 'explanation', 'cause' and other second-order aspects of history are key to the sense they may make of content.

Our findings are also consistent with research findings on substantive conceptual development in history. Carretero and Lee, for example, propose a model of the direction of progression in substantive concepts that posits an overall movement from the concrete to the abstract as key, exemplified, in the case of knowledge of institutions, in a shift from 
a focus on 'personalization' to a focus on 'institutionalization'. ${ }^{51}$ Our exploratory research provides exemplification of what movement from the concrete to the abstract can look like in one area of historical understanding, however, it perhaps raises more questions than it can answer. 'Does the linguistic release the conceptual?' Woodcock asked in an influential practitioner article some years ago, and the question is highly pertinent to our results. ${ }^{52}$ Many of our findings are centrally about change in linguistic sophistication (as, for example, our differentiation of nominalisations into types in Table 4 showed). How far increased sophistication in understanding is (a) driven by or (b) the driver of increasing linguistic sophistication, is a question that it would be very valuable to explore but that is beyond the scope of this article.

In general, there has been much more research on progression in second-order procedural concepts (such as 'cause') than on substantive historical concepts and colligations (such as 'the Holocaust'). The findings of Foster et al - a study that is internationally ground-breaking in both its scale and sophistication - and the tentative findings of the small scale exploratory analysis reported in this article, both argue for the importance of increasing research attention on substantive issues. Foster et al. point to the power of 'collective' representations in shaping the form of students' knowledge and understanding. Our analysis suggests that a purely functional approach can reveal an important dimension of conceptual development - the grammar of students' substantive thinking. Further research on the ways in which grammar both enables and constrains understandings of historical agents, actions, events and processes, would, it seems to us, be both informative and valuable.

In addition to its substantive focus on progression, this article has also sought to discuss how empirical social scientific research methods and methodologies can be used to help us describe young people's knowledge and understanding of the Holocaust. As 
highlighted, a key consideration for researchers is to define the concept they are measuring. When examining knowledge and understanding of the Holocaust it is essential to recognise that knowledge and understanding are not synonymous. If one is seeking to find the scope of students' knowledge of singular factual propositions in a large sample, then using questions that can be quickly and objectively scored and used in statistical analyses (like multiple choice questions) is one way to achieve this. However, it is important to recognise these types of question cannot measure students' understanding of the Holocaust as an historical colligation. To do this, researchers need to utilise research methods that collect qualitative data. This can be done as part of a mixed methods approach, so that the study can draw on the merits of both quantitative and qualitative methods.

One means of collecting qualitative data is to give students open questions where they construct their own answers as exemplified in this article. The data collected using the question 'can you describe in one or two sentences what you think the Holocaust was' has shown that even where students provide short answers, rich data can be gathered. As we have demonstrated, this also opens up a number of possibilities in terms of the approach one takes to analysis. When working with a data set comprised of responses from thousands of students, it can be fruitful to conduct exploratory analyses on a subsample of the data, as we have set out to do in this article.

The analysis of data in this study sought to be exploratory in nature. Consequently, a small subsample of the CfHE data set was used and we acknowledge this may not be representative of the full sample of students. The small subsample also meant it was inappropriate to conduct analyses to assess statistical significance (for example, to determine whether the difference between the number of year 7 and year 12 students identifying 'Actors' in their answers was statistically significant). An area for future 
research will be to conduct transitivity analysis, ontological analysis and conceptual analysis with a larger sample that includes students from across all seven year groups. We also note that the wording of the question may have influenced the content of the students' responses, and this is something that is being examined in work currently underway in the UCL Centre for Holocaust Education.

Robust research to examine students' knowledge and understanding of the Holocaust is wanting. It is important that, going forward, researchers conduct studies which recognise the conceptual differences between knowledge and understanding. The research methods that are utilised and the analyses that are performed should be guided by clear research questions, with a mixed methods approach providing a means to explore different aspects of knowledge and understanding.

\section{References}

Bischoping, Katherine. "Method and Meaning in Holocaust-Knowledge Surveys." Holocaust and Genocide Studies 12, no. 3 (1998): 454-474.

Blaikie, Norman. Approaches to Social Enquiry: Advancing knowledge. Cambridge: Polity, 2007 (2 $2^{\text {nd }}$ Edition).

British Broadcasting Corporation (BBC) (2014) GCSE Bitesize, History, Assassination at Sarajevo. Retrieved $1^{\text {st }}$ April 2016 from http://www.bbc.co.uk/schools/gcsebitesize/history/mwh/ir1/assassinationrev1.shtml

Carretero, Mario and Peter Lee. "Learning Historical Concepts.” In The Cambridge Handbook of the Learning Sciences, edited by R. Keith Sawyer, 587-604. Cambridge: Cambridge University Press, 2014. 
Carrington, Bruce and Geoffrey Short. "Holocaust Education, Anti-racism and Citizenship." Educational Review 49, no. 3 (1997): 271-282.

Chapman, Arthur, Chris Edwards, Emily Goldsmith, Kay Andrews, John Brown, Adrian Burgess, Evangelos Himonides, et al. Evaluation of the Holocaust Educational Trust's Lessons from Auschwitz Project: Final report. London: Institute of Education, 2011.

Coffin, Caroline, Jim Donohue and Sarah North. Exploring English Grammar: From formal to functional. London and New York: Routledge, 2009.

Donovan, M. Suzanne, and John D. Bransford. "Introduction.” In How Students Learn: History in the classroom, edited by Suzanne M. Donovan and John D. Bransford, 1-26. Washington DC: National Academies Press, 2005.

Foster, Stuart, Alice Pettigrew, Andy Pearce, Rebecca Hale, Adrian Burgess, Paul Salmons, and Ruth-Anne Lenga. What do students know and understand about the Holocaust? Evidence from English secondary schools. London: UCL Institute of Education, 2016.

Gibbs. Graham. Qualitative Data Analysis: Explorations With Nvivo: Explorations with NVivo. Maidenhead: Open University Press, 2002.

Halliday, M.A.K. and Christian, M.I.M., Matthiessen. Halliday's Introduction to Functional Grammar, Abingdon and New York: Routledge, 2014. 
Ivanova, Elena. "Ukrainian High School Students' Understanding of the Holocaust." Holocaust and Genocide Studies (2004): 402-420.

Jedwab, Jack. "Measuring Holocaust knowledge and its impact: A Canadian case study." Prospects (2010) no. 40: 273-287.

Johnson, Burke R. and Anthony J. Onwuegbuzie. "Mixed Methods Research: A Research Paradigm Whose Time Has Come.” Educational Researcher 33, no. 7 (2004): 14-26.

Johnson Burke R., Anthony J. Onwuegbuzie and Lisa A. Turner. "Toward a Definition of Mixed Method Research.” Journal of Mixed Methods Research 1, no. 2 (2007): 112133.

Kelle, Udo. "Combining qualitative and quantitative methods in research practice: purposes and advantages." Qualitative Research in Psychology 3, no. 4 (2006): 293311.

Kuukkanen, J.M. Postnarrativist Philosophy of Historiography. Basingstoke: Palgrave Macmillan, 2015.

Lee, Peter, and Denis Shemilt. "Is any explanation better than none? Over-determined narratives, senseless agencies and one-way streets in students' learning about cause and consequence in history." Teaching History, 137, (2009): 42-49. 
Lee, Peter. "Putting principles into practice: understanding history." In How Students Learn: History in the classroom, edited by Suzanne M. Donovan and John D.

Bransford, 31-74. Washington DC: National Academies Press, 2005.

Lévesque, Stéphane. Thinking Historically: Educating Students for the Twenty-First Century. Toronto: University of Toronto Press, 2008.

Onwuegbuzie, Anthony J. and Nancy L. Leech. "Enhancing the Interpretation of Significant Findings: The Role of Mixed Methods Research.” The Qualitative Report 9, no. 4 (2004): 770-792.

Morgan, David L. "Practical Strategies for Combining Qualitative and Quantitative Methods: Applications to Health Research.” Qualitative Health Research 8, no. 3 (1998): 362-376.

Morgan, David L. "Paradigms lost and pragmatism required: methodological implications of combining qualitative and quantitative methods." Journal of Mixed Methods Research 1, no. 1 (2007): 48-76.

Newman, Isadore, Carolyn S. Ridenour, Carole Newman and George Mario Paul DeMarco. "A Typology of Research Purposes and its Relationship to Mixed Methods." In Handbook of Mixed Methods in Social and Behavioural Research, edited by Abbas Tashakkori and Charles Teddlie, 167-188. California: Sage Publications, 2003. 
Pettigrew, Alice, Stuart Foster, Jonathan Howson, Paul Salmons, Ruth-Anne Lenga and Kay Andrews. Teaching About the Holocaust in English Secondary Schools: An empirical study of national trends, perspectives and practice. London: Institute of Education, 2009.

Rogers, Rick. "Frameworks for Big History: Teaching History at Its Lower Resolutions." In Master Class in History Education: Transforming Teaching and Learning edited by Christine Counsell, Katharine Burn and Arthur Chapman. London: Bloomsbury Academic, 2016.

Seixas, Peter. “A Model of Historical Thinking”. Educational Philosophy and Theory. Published online: 27 Oct 2015. DOI: 10.1080/00131857.2015.1101363

Shaw, Martin. What is Genocide? Cambridge: Polity Press, 2015.

Strauss, Anselm, and Juliet Corbin Basics of Qualitative Research: Techniques and Processes for Developing Grounded Theory. Thousand Oaks, London and New Delhi: Sage Publications, 1998.

Tamir, Pinchas. "Justifying the selection of answers in multiple choice items." International Journal of Science Education 12, no. 5 (1990): 563-573.

Thompson, Don. "Colligatoin and History Teaching” In Studies in the Nature and Teaching of History by Wyndham Hedley Burston and Donald Thompson. London: Routledge and K. Paul, 1967. 
Van Drie, Jannet, and Carla van Boxtel. "Historical Reasoning: Towards a framework for analyzing students' reasoning about the past". Educational Psychology Review, 20, no. 2 , (2008): 87-110.

Walsh, William.H. "Colligatory Concepts in History." In The Philosophy of History, edited by Patrick L. Gardiner, 127-144. Oxford: Oxford University Press, 1970.

Woodcock, James. "Does the linguistic release the conceptual? Helping Year 10 to improve their causal reasoning." Teaching History, 119 (2005): 5-14.

\footnotetext{
${ }^{1}$ Foster, What do Students Know

${ }^{2}$ Donovan and Bransford, eds. How Students Learn, 1-2.

${ }^{3}$ BBC. GCSE Bitesize, History.

${ }^{4}$ Ibid.
} 
${ }^{5}$ The discussion in this section depends upon, inter alia, Lee. 'Putting principles into practice', Lévesque. Thinking Historically, Seixas. A Model of Historical Thinking and van Drie and van Boxtel. 'Historical Reasoning'.

${ }^{6}$ Walsh, Colligatory Concepts in History; and Kuukkanen, Postnarrativist Philosophy.

${ }^{7}$ We borrow the metaphor of understanding history at different resolutions and of 'zooming' in and out to do so from Rogers. 'Frameworks for Big History'.

${ }^{8}$ Shaw, What is Genocide?

${ }^{9}$ Pettigrew et al., Teaching about the Holocaust, 77

${ }^{10}$ Foster et al., What do Students Know, 8

${ }^{11}$ Tamir, Multiple Choice Items, 563

${ }^{12}$ Bischoping, Meaning in Holocaust-Knowledge Surveys, 455

${ }^{13}$ Carrington and Short, Holocaust Education, Anti-racism, Citizenship, 274-275

${ }^{14}$ Foster et al., What do Students Know, 192-194

${ }^{15}$ Foster et al., What do Students Know, 190

${ }^{16}$ Ivanova, Ukrainian Students' Holocaust Understanding, 402-420

${ }^{17}$ Johnson and Onwuegbuzie, Mixed Methods Research, 20

${ }^{18}$ Jedwab, Measuring Holocaust Knowledge, 277

${ }^{19}$ Foster et al., What do Students Know, 8

${ }^{20}$ Jedwab, Measuring Holocaust Knowledge, 277

${ }^{21}$ Foster et al., What do Students Know, 161-164.

${ }^{22}$ Bischoping, Meaning in Holocaust-Knowledge Surveys, 455

${ }^{23}$ Johnson et al., Mixed Methods Research Definition, 123

${ }^{24}$ Onwuegbuzie and Leech, Interpretation of Mixed Methods, 771

${ }^{25}$ Morgan, Strategies for combining methods, 362-376

${ }^{26}$ Kelle, Combining qualitative quantitative methods, 293-311

${ }^{27}$ Morgan, Paradigms lost, pragmatism required; Newman, Typology of Research Purposes

${ }^{28}$ Johnson and Onwuegbuzie, Mixed Methods Research, 14-26 
${ }^{29}$ Foster et al., What do Students Know, 23-34

${ }^{30}$ Foster et al., What do Students Know, 31-34

${ }^{31}$ Blaikie. Approaches to Social Enquiry.

${ }^{32}$ Strauss and Corbin. Basics of Qualitative Research.

${ }^{33}$ Foster et al., What do Students Know, 37-69

${ }^{34}$ Foster et al., What do Students Know, 29.

${ }^{35}$ Foster et al., What do Students Know, 23-34.

${ }^{36}$ Foster et al., What do Students Know, 40

${ }^{37}$ Foster et al., What do Students Know, 36-69, 231 and 249-250.

${ }^{38}$ Foster et al., What do Students Know, 44 and 249-250.

${ }^{39}$ Foster et al., What do Students Know, 62.

${ }^{40}$ Foster et al., What do Students Know, 42-43.

${ }^{41}$ Gibbs. Qualitative Data Analysis.

${ }^{42}$ Coffin, Donohue and North, Exploring English Grammar and Halliday and Matthiessen, Halliday's Functional Grammar.

${ }^{43}$ Halliday and Matthiessen, Halliday's Functional Grammar, 83.

${ }^{44}$ Foster, et al. What do Students Know, 65-66; Pettigrew, et al.. Teaching About the Holocaust, 65-70; and Chapman, et al. Lessons from Auschwitz, 89-93.

${ }^{45}$ We adopt the terms 'Actors' and 'Acted-upon' here - rather than more conventional grammatical terms (such as 'patient' or 'goal') because of some unwelcome connotations that conventional terms might have in the context of our subject matter. The 'Acted-upon' function is referred to as 'semantic object' to indicate that it is not identical in meaning with the grammatical category 'direct object'.

46 'Nominalisation is a type of grammatical metaphor. In formal written English there is a tendency to represent events, qualities of objects and events, and logical connections, not in their most 'natural' or congruent forms as verbs but as nouns. This is particularly the case in academic, technical, and specialised uses of English. The use of nominalisation increases 
dramatically in topics that are based on abstract concepts, properties, and theories. Arguably, without the ability to nominalise, it would be difficult to develop many scientific notions (e.g. evaporation, radiation, etc.). Coffin, Donohue and North, Exploring English Grammar, $422-3$

${ }^{47}$ Coffin, Donohue and North, Exploring English Grammar, 308-9.

${ }^{48}$ Syntax and orthography have been corrected in all respondent descriptions throughout this article to enhance readability and comprehension.

${ }^{49}$ We coded items like 'during World War 2' as referencing the 'situation' rather than time because these items are ambiguous and could mean (a) 'between 1939-1945' or (b) 'when there was a war taking place'. Foster et al. coded such terms as referencing time (What do Students Know, 54).

${ }^{50}$ Lee, Putting principles into practice; and Lee and Shemlt. Explanation better than none?

${ }^{51}$ Carretero and Lee. Learning Historical Concepts, 590.

${ }^{52}$ Woodcock., Linguistic Release the Conceptual?

Table 1. 'Participants' by category analysed by year group: 'Actors'

\begin{tabular}{|l|l|c|c|c|}
\hline No. & Actor category & Year 7 & Year 8 & Year 12 \\
\hline 1 & $\begin{array}{l}\text { 'They'[No further identifying } \\
\text { detail] }\end{array}$ & $5.1 \%$ & $0.0 \%$ & $0.0 \%$ \\
\hline 2 & Some people [survived] & $2.6 \%$ & $0.0 \%$ & $0.0 \%$ \\
\hline 3 & The 'shower' & $2.6 \%$ & $0.0 \%$ & $0.0 \%$ \\
\hline 4 & Hitler & $23.1 \%$ & $40.0 \%$ & $13.6 \%$ \\
\hline 5 & The Germans & $33.3 \%$ & $33.3 \%$ & $9.1 \%$ \\
\hline 6 & The Jews & 0.0 & $6.7 \%$ & $4.5 \%$ \\
\hline 7 & The Nazis & $20.5 \%$ & $6.7 \%$ & $22.7 \%$ \\
\hline 8 & Nazi Germany & $0.0 \%$ & $6.7 \%$ & $9.1 \% \quad 43$ \\
\hline
\end{tabular}




\begin{tabular}{|l|l|c|c|c|}
\hline 9 & The Nazi Party & $0.0 \%$ & $6.7 \%$ & $9.1 \%$ \\
\hline 10 & The Nazi government & $0.0 \%$ & $0.0 \%$ & $9.1 \%$ \\
\hline 11 & $\begin{array}{l}\text { The Nazi party and their leader } \\
\text { Hitler }\end{array}$ & $12.8 \%$ & $0.0 \%$ & $22.7 \%$ \\
\hline & Total and 'N' & $\begin{array}{r}100 \% \\
(\mathrm{~N}=42)\end{array}$ & $\begin{array}{c}100 \% \\
(\mathrm{~N}=15)\end{array}$ & $\begin{array}{c}100 \% \\
(\mathrm{~N}=22)\end{array}$ \\
\hline
\end{tabular}

* ' $\mathrm{N}$ ' in all columns denotes the number of instances coded not the number of respondents (which, in all tables, was 30 respondents per year group)

Table 2. 'Participants' by category analysed by year group: 'the Acted-upon'

\begin{tabular}{|l|l|c|c|c|}
\hline No. & Acted-upon category & Year 7 & Year 8 & Year 12 \\
\hline 1 & Jews & $61.4 \%$ & $76.3 \%$ & $57.6 \%$ \\
\hline 2 & Disabled people & $0.0 \%$ & $2.6 \%$ & $6.8 \%$ \\
\hline 3 & Homosexuals & $0.0 \%$ & $2.6 \%$ & $6.8 \%$ \\
\hline 4 & Minority groups & $0.0 \%$ & $0.0 \%$ & $6.8 \%$ \\
\hline 5 & Gypsies & $0.0 \%$ & $2.6 \%$ & $5.1 \%$ \\
\hline 6 & 'Undesirables' & $0.0 \%$ & $0.0 \%$ & $3.4 \%$ \\
\hline 7 & Communists & $0.0 \%$ & $0.0 \%$ & $1.7 \%$ \\
\hline 8 & Blacks & $5.3 \%$ & $0.0 \%$ & $0.0 \%$ \\
\hline 9 & Foreigners & $0.0 \%$ & $2.6 \%$ & $0.0 \%$ \\
\hline
\end{tabular}




\begin{tabular}{|l|l|c|c|c|}
10 & Germans & $0.0 \%$ & $2.6 \%$ & $0.0 \%$ \\
\hline 11 & Europe / European & $3.5 \%$ & $0.0 \%$ & $5.1 \%$ \\
\hline 12 & In Germany & $0.0 \%$ & $0.0 \%$ & $1.7 \%$ \\
\hline 13 & Poland / In Poland & $1.8 \%$ & $0.0 \%$ & $1.7 \%$ \\
\hline 14 & In Russia & $0.0 \%$ & $0.0 \%$ & $1.7 \%$ \\
\hline 15 & Number only & $0.0 \%$ & $0.0 \%$ & $0.0 \%$ \\
\hline 16 & People only & $15.8 \%$ & $5.3 \%$ & $1.7 \%$ \\
\hline 17 & Adults & $1.8 \%$ & $0.0 \%$ & $0.0 \%$ \\
\hline 18 & Children & $3.5 \%$ & $0.0 \%$ & $0.0 \%$ \\
\hline 19 & Elderly & $1.8 \%$ & $0.0 \%$ & $0.0 \%$ \\
\hline 20 & A camp & $3.5 \%$ & $0.0 \%$ & $0.0 \%$ \\
\hline 21 & Heads & $0.0 \%$ & $2.6 \%$ & $0.0 \%$ \\
\hline 22 & Clothes, suitcases, skulls & $1.8 \%$ & $0.0 \%$ & $0.0 \%$ \\
\hline & Totals & $100 \%$ & $100 \%$ & $100 \%$ \\
& & $(\mathrm{~N}=57)$ & $(\mathrm{N}=38)$ & $(\mathrm{N}=59)$ \\
\hline
\end{tabular}

* ' $\mathrm{N}$ ' in all columns denotes the number of instances coded not the number of respondents (which, in all tables, was 30 respondents per year group)

Table 3. 'Processes' by category analysed by year group: Verb categories and nominalisation

\begin{tabular}{|l|l|c|c|c|}
\hline No. & Process category & Year 7 & Year 8 & Year 12 \\
\hline 1 & Material & $80.0 \%$ & $75.0 \%$ & $30.5 \%$ \\
\hline 2 & Mental & $7.3 \%$ & $10.0 \%$ & $11.9 \%$ \\
\hline 3 & Relational & $1.8 \%$ & $1.7 \%$ & $0.0 \%$ \\
\hline 4 & Existential & $3.6 \%$ & $5.0 \%$ & $20.3 \%$ \\
\hline 5 & Verbal & $1.8 \%$ & $0.0 \%$ & $0.0 \%$ \\
\hline 6 & Nominalisation & $5.5 \%$ & $8.3 \%$ & $37.3 \%$ \\
\hline & Totals & $\begin{array}{c}100 \% \\
(\mathrm{~N}=55)\end{array}$ & $\begin{array}{c}100 \% \\
(\mathrm{~N}=60)\end{array}$ & $\begin{array}{c}100 \% \\
(\mathrm{~N}=59)\end{array}$ \\
\hline
\end{tabular}


* ' $\mathrm{N}$ ' in all columns denotes the number of instances coded not the number of respondents (which, in all tables, was 30 respondents per year group)

Table 4. Nominalisations categorized by lexical features

\begin{tabular}{|l|l|c|c|c|}
\hline Type & Process category & Year 7 & Year 8 & Year 12 \\
\hline A & Death & 1 & 1 & 0 \\
\hline A & Killing & 1 & 1 & 3 \\
\hline A & Murder & 0 & 0 & 4 \\
\hline A & Torture & 0 & 1 & 0 \\
\hline B & Annihilation & 0 & 0 & 1 \\
\hline B & Discrimination & 0 & 1 & 0 \\
\hline B & Extermination & 1 & 0 & 5 \\
\hline B & Genocide & 0 & 1 & 6 \\
\hline B & Persecution & 0 & 0 & 1 \\
\hline B & Prejudice & 0 & 0 & 1 \\
\hline C & Final Solution & 0 & 1 \\
\hline
\end{tabular}




\begin{tabular}{|l|l|c|c|c|}
\hline & Totals & $\mathrm{N}=3$ & $\mathrm{~N}=5$ & $\mathrm{~N}=22$ \\
\hline
\end{tabular}

$*$ ' $\mathrm{N}$ ' in all columns denotes the number of instances coded not the number of respondents (which, in all tables, was 30 respondents per year group)

Table 5. 'Circumstances' by category analysed by year group

\begin{tabular}{|l|l|c|c|c|}
\hline No. & Circumstance category & Year 7 & Year 8 & Year 12 \\
\hline 1 & Spatial location & $9.1 \%$ & $31.8 \%$ & $19.6 \%$ \\
\hline 2 & Time location & $0.0 \%$ & $0.0 \%$ & $6.5 \%$ \\
\hline 3 & Means & $9.1 \%$ & $13.6 \%$ & $6.5 \%$ \\
\hline 4 & Situation & $31.8 \%$ & $25.0 \%$ & $23.9 \%$ \\
\hline 5 & Explanation & $11.4 \%$ & $11.4 \%$ & $19.6 \%$ \\
\hline 6 & Scale & $27.3 \%$ & $13.6 \%$ & $17.4 \%$ \\
\hline 7 & Consequences & $0.0 \%$ & $0.0 \%$ & $2.2 \%$ \\
\hline 8 & Evaluation & $11.4 \%$ & $5.5 \%$ & $4.3 \%$ \\
\hline & Totals & $100 \%$ & $100 \%$ & $100 \%$ \\
& $(\mathrm{~N}=44)$ & $(\mathrm{N}=46)$ & $(\mathrm{N}=46)$ \\
\hline
\end{tabular}

* ' $\mathrm{N}$ ' in all columns denotes the number of instances coded not the number of respondents (which, in all tables, was 30 respondents per year group) 
Table 6. 'Circumstances' of explanation analysed by year group

\begin{tabular}{|c|l|c|c|c|}
\hline No. & Circumstance category & Year 7 & Year 8 & Year 12 \\
\hline 1 & Political & $0.0 \%$ & $2.0 \%$ & $27.3 \%$ \\
\hline 2 & Ideological & $0.0 \%$ & $0.0 \%$ & $54.5 \%$ \\
\hline 3 & Religious & $60.0 \%$ & $0.0 \%$ & $9.1 \%$ \\
\hline 4 & Personal animosity & $40.0 \%$ & $40.0 \%$ & $0.0 \%$ \\
\hline 5 & Discrimination & $0.0 \%$ & $0.0 \%$ & $9.1 \%$ \\
\hline 6 & Image & $0.0 \%$ & $20.0 \%$ & $0.0 \%$ \\
\hline 7 & Difference & $0.0 \%$ & $20.0 \%$ & $0.0 \%$ \\
\hline & Totals & $\begin{array}{c}100 \% \\
(\mathrm{~N}=5)\end{array}$ & $\begin{array}{c}100 \% \\
(\mathrm{~N}=5)\end{array}$ & $\begin{array}{c}100 \% \\
(\mathrm{~N}=11)\end{array}$ \\
\hline
\end{tabular}

* ' $\mathrm{N}$ ' in all columns denotes the number of instances coded not the number of respondents (which, in all tables, was 30 respondents per year group) 
Table 7. 'Ontologies' of the Holocaust analysed by year group

\begin{tabular}{|c|l|c|c|c|}
\hline No. & Ontological category & Year 7 & Year 8 & Year 12 \\
\hline 1 & Act & 53.8 & 48.1 & 19.2 \\
\hline 2 & Event & 11.5 & 22.2 & 7.7 \\
\hline 3 & People & 0.0 & 3.7 & 0.0 \\
\hline 4 & Period & 19.2 & 3.7 & 0.0 \\
\hline 5 & Place & 7.7 & 7.4 & 0.0 \\
\hline 6 & Process & 7.7 & 14.8 & 73.1 \\
\hline & Totals & $\begin{array}{c}100 \% \\
(\mathrm{~N}=26)\end{array}$ & $\begin{array}{c}100 \% \\
(\mathrm{~N}=28)\end{array}$ & $\begin{array}{c}100 \% \\
(\mathrm{~N}=26)\end{array}$ \\
\hline
\end{tabular}

* ' $\mathrm{N}$ ' in all columns denotes the respondents coded (of a possible total of 30 respondents per year group). 
Table 8. 'Genocide': the incidence of categories analysed by year group

\begin{tabular}{|c|l|c|c|c|}
\hline No. & Task category & Year 7 & Year 8 & Year 12 \\
\hline 1 & Genocidal and exclusive & 6 & 3 & 9 \\
\hline 2 & Genocidal and inclusive & 2 & 1 & 6 \\
\hline 3 & Non-genocidal and exclusive & 15 & 15 & 11 \\
\hline 4 & Non-genocidal and inclusive & 3 & 4 & 1 \\
\hline 5 & $\begin{array}{l}\text { Static and differentiated (genocidal } \\
\text { towards Jewish people and non- } \\
\text { genocidal towards others and } \\
\text { constant over time) }\end{array}$ & 0 & 0 & 1 \\
\hline 6 & $\begin{array}{l}\text { Dynamic and differentiated } \\
\text { (evolving, during its course, to } \\
\text { become genocidal towards Jewish } \\
\text { people and non-genocidal towards } \\
\text { others) }\end{array}$ & 0 & 0 & 0 \\
\hline 7 & No relevant material & 4 & 7 & 2 \\
\hline & Totals & $\mathrm{N}=30$ & $\mathrm{~N}=30$ & $\mathrm{~N}=30$ \\
\hline
\end{tabular}

* ' $\mathrm{N}$ ' in all columns denotes the number of respondents. 
Table 9. Genocide: exemplification of categories from across year groups

\begin{tabular}{|c|l|l|}
\hline No. & Task category & \multicolumn{1}{c|}{ Exemplification } \\
\hline 1 & $\begin{array}{l}\text { Genocidal and } \\
\text { exclusive }\end{array}$ & $\begin{array}{l}\text { Year 7 when Adolf Hitler tried to kill all the Jews in the world. } \\
\text { The Holocaust was the attempted extermination of Jewish } \\
\text { people. } \\
\text { Year 12 }\end{array}$ \\
\hline 2 & $\begin{array}{l}\text { Genocidal and } \\
\text { inclusive }\end{array}$ & $\begin{array}{l}\text { The Holocaust was when the German people captured all of the } \\
\text { Jews and most of the people in Europe and sent them to a } \\
\text { tortured, starved and eventually killed by the Nazis and their } \\
\text { German leader: Adolf Hitler. } \\
\text { Year 8 }\end{array}$ \\
\hline 3 & $\begin{array}{l}\text { When the Jews were persecuted by the Nazis } \\
\text { Year 7 } \\
\text { The Holocaust was when the Nazis killed millions of innocent } \\
\text { Jewish people because they believed the Jews were to blame for } \\
\text { all of Germany's problems. } \\
\text { Year 12 }\end{array}$ \\
\hline
\end{tabular}




\begin{tabular}{|c|l|l|}
\hline 4 & $\begin{array}{l}\text { A time in history when people and children were sent off to a } \\
\text { building and were ether gassed or were beaten to death. They } \\
\text { also had some children working hard. } \\
\text { Year 7 } \\
\text { Non-genocidal } \\
\text { and inclusive } \\
\text { The Nazi's were a group of Germans led by Adolf Hitler who } \\
\text { believed racist things and killed many people because of it. } \\
\text { Particularly Jewish people. } \\
\text { Year 8 }\end{array}$ \\
\hline 5 & $\begin{array}{l}\text { Static and } \\
\text { differentiated }\end{array}$ & $\begin{array}{l}\text { The Holocaust was the genocide of millions of Jews, along with } \\
\text { the murder of other minority groups. } \\
\text { Year 12 }\end{array}$ \\
\hline
\end{tabular}

